\title{
Experiment Study of Reverse Demulsifier on Simulated Water Sample Treatment at Different Oscillation Time and Different Concentrations of Drugging
}

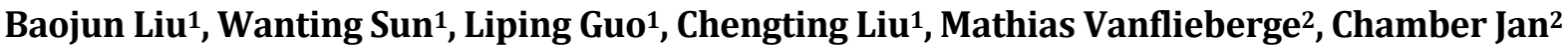 \\ ${ }^{1}$ The College of Petroleum Engineering, Northeast Petroleum University, Daqing, China \\ ${ }^{2}$ Catholic University of Louvain, Brussels, Belgium \\ Email: liubaojun@nepu.edu.cn
}

Received 12 November 2015; accepted 7 December 2015; published 10 December 2015

Copyright (C) 2015 by authors and Scientific Research Publishing Inc.

This work is licensed under the Creative Commons Attribution International License (CC BY). http://creativecommons.org/licenses/by/4.0/

c) (i) Open Access

\begin{abstract}
In recent years, the water content of oilfield production fluid is high and there is a large amount of oily sewage. In order to improve the capability of sewage treatment, usually using demulsifier for oily sewage processing. This article uses simulated water sample to test the treatment effect of the optimized reverse demulsifier at different oscillation time. As the increase of action time and oscillation, the average size of droplets increases and the amount of the droplets under $1 \mu \mathrm{m}$ decreases.
\end{abstract}

\section{Keywords}

Reverse Demulsifier, Simulated Water Sample, Oil Droplet Size

\section{Introduction}

At present, the moisture content of the produced liquid has been reached over 95\% in Daqing Oilfield. Therefore, to improve the rate of oily sewage separation and enhance the ability in waste-water treatment are becoming an important task [1]. There are many processing methods of oily sewage: electrolysis, gravity separation. In this paper, we study on the method of demulsifier. Its treatment effect is in connection with the drugging location, drugging concentration and oscillation time. In this paper, we chose previous optimal selection demulsifier and indoor simulation of produced water to test the treatment effect of optimal selection reagent in different drugging concentration and different oscillation time [2]. 


\section{Experiment}

\subsection{Preparation of Simulation Water Sample and Experimental Procedure}

Simulation water sample consisting of two parts: oil sample and water sample. Oil sample: outer transportation crude oil of Daqing Oilfield co.LTD. the first Oil Production Plant Zhongyi Joint Station; Water sample: artificial water sample which prepared according to the free water produced fluid's water quality analysis data. The date gets from oil well of Zhongyi Joint Station, it's formula is: $\mathrm{w}(\mathrm{NaCl})=0.1995 \%$; $\mathrm{w}\left(\mathrm{NaHCO}_{3}\right)=0.3024 \%$; $\mathrm{w}\left(\mathrm{Na}_{2} \mathrm{CO}_{3}\right)=0.0171 \% ; \mathrm{w}\left(\mathrm{Na}_{2} \mathrm{SO}_{4}\right)=0.0001 \% ; \mathrm{w}\left(\mathrm{CaCl}_{2}\right)=0.0002 \% ; \mathrm{w}\left(\mathrm{MgCl}_{2} \cdot 6 \mathrm{H}_{2} \mathrm{O}\right)=0.0007 \%$ [3]; polymer: polyacrylamide, relative molecular weight of 3.5 million; surfactant: OP-10.

The first step of preparing simulated water sample is the mother liquid. Mother liquid is an emulsion, it's oil content is 50\%. The step of preparing: Add $1500 \mathrm{mg} / \mathrm{L}$ polymer (molecular weights of 3.5 million) to the jar of $5000 \mathrm{ml}, 100 \mathrm{~g}$ of distilled water, it's content of surfactant (OP-10) is $1000 \mathrm{mg} / \mathrm{L}$; The purpose of adding polymer and surfactant is to prepare a stable emulsion. Add $100 \mathrm{~g}$ of oil sample to a jar then put the jar in $45^{\circ} \mathrm{C}$ constant temperature water bath for $60 \mathrm{~min}$. Use the oil sample and the water sample in jars to prepare oil particulate mother liquid of $50 \%$ oil content (with the measurement of particles distribution instrument, the average diameter of oil particulate is $2.44 \mu \mathrm{m}$, the distribution of oil particulate diameter is $0.85-5.85 \mu \mathrm{m}$ ). Date processing apparatus is T25 type of homogeneous instrument produced by the IKA Company in Germany. Emulsify in 20,000 r/min rotating speed for $7 \mathrm{~min}$. In this process, homogeneous instrument placed in $45^{\circ} \mathrm{C}$ incubator to keep the temperature constant.

The mother liquid is ready, we can prepare the simulated water sample. The process: Add $398.4 \mathrm{~g}$ of water sample into a plastic bottle of $600 \mathrm{ml}$ then added $1.6 \mathrm{~g}$ of oil particulate mother liquid prepared already. After shaking with hands for 20 times, we get the simulated water sample of $2000 \mathrm{mg} / \mathrm{L}$ oil content. Now the content of polymer is $3 \mathrm{mg} / \mathrm{L}$ in the water sample, it will not influence the property of water sample.

\subsection{Treatment Effect Experiment in Different Drugging Concentration}

Refer to the drug concentration of practical field. The choices of drugging concentration are $5 \mathrm{mg} / \mathrm{L}, 10 \mathrm{mg} / \mathrm{L}$, $20 \mathrm{mg} / \mathrm{L}$. To facilitate the evaluation, each oscillation time has two water samples, an adding sample, a blank sample. According to the experimental results of previous optimal selection reagent, the reagent in adding sample is S1 [4].

Experimental procedure: put two plastic bottles with simulated water sample in the $45^{\circ} \mathrm{C}$ constant temperature water bath for $60 \mathrm{~min}$, then add $1.6 \mathrm{~g}$ of oil particulate mother liquid and shake 20 times with hand. Of which one plastic bottle added S1 of $5 \mathrm{mg} / \mathrm{L}$, making it as the adding sample, another bottle is the blank sample. Add about $8 \mathrm{~g}$ crude oil into both of bottles, then put bottles in vibrator shake in $360 \mathrm{r} / \mathrm{min}$ for $15 \mathrm{~min}$. Set the vibrator in $45^{\circ} \mathrm{C}$ incubator during shaking, to keep a constant temperature. After shaking, make bottles standing for $15 \mathrm{~min}$ then measure the oil content and the distribution of oil particulate diameter in lower water. Change drugging concentration. Repeat the same method. Drugging concentration is respectively $10 \mathrm{mg} / \mathrm{L}, 20 \mathrm{mg} / \mathrm{L}$.

\subsection{Treatment Effect Experiment at Different Oscillation Time}

Oscillation time determined by the flowing time of produced water in pipe. The choices of oscillation time are $15 \mathrm{~min}$ (between booster station and joint station), $30 \mathrm{~min}$ (between metering station and booster station, close to booster station), 60 min (between metering station and booster station, in the middle), 90 min (between metering station and booster station, close to metering station), $120 \mathrm{~min}$ (between oil well and joint station).

To facilitate the evaluation, every oscillation time has two water samples, an adding sample, a blank sample. According to the experimental results of previous optimal selection reagent, the reagent in adding sample is S1, concentration is $20 \mathrm{mg} / \mathrm{L}$. Experimental procedure: put two plastic bottles with simulated water sample in the $45^{\circ} \mathrm{C}$ constant temperature water bath for $60 \mathrm{~min}$, then add $1.6 \mathrm{~g}$ of oil particulate mother liquid and shake 20 times with hand. Of which one plastic bottle added S1 of $20 \mathrm{mg} / \mathrm{L}$, making it as the adding sample, another botthe is the blank sample. Add about $8 \mathrm{~g}$ crude oil into both of bottles, then put bottles in vibrator shake in 360 $\mathrm{r} / \mathrm{min}$ for $15 \mathrm{~min}$. Set the vibrator in $45^{\circ} \mathrm{C}$ incubator during shaking, to keep a constant temperature. After shaking, make bottles standing for $15 \mathrm{~min}$, then measure the oil content and the distribution of oil particulate diameter in lower water. Change oscillation time. Repeat the same method. Oscillation time is respectively $30 \mathrm{~min}, 60$ min, $90 \mathrm{~min}, 120 \mathrm{~min}$ [5]. 


\subsection{Evaluation Parameter}

Drugging effect evaluation has three ways, first is according to the minimum $10 \%$ particle diameter, D10; second is according to oil droplet under $1 \mu \mathrm{m}, \mathrm{C}_{1 \mu \mathrm{m}}$; third is according to oil droplet volume average particle diameter, $\mathrm{D}[4,3]$. Obtained Oil removal rate from the change of oil content, $\mathrm{P}_{1 \mu \mathrm{m}}$.

Concrete evaluation parameter and calculation formula as follows.

The calculation formula of $\mathrm{C}_{1 \mu \mathrm{m}}$ :

$$
\mathrm{C}_{1 \mu \mathrm{m}}=\mathrm{V}_{1 \mu \mathrm{m}} \times \mathrm{C}_{i}
$$

Among them: $\mathrm{V}_{1 \mu \mathrm{m}}$-Concentration of oil droplet which particle diameter under $1 \mu \mathrm{m}$;

$\mathrm{C}_{\mathrm{i}}$ - Oil content in sample.

By the evaluation index, the smaller the $C_{1 \mu m}$ means drugging do better on reducing oil droplet under $1 \mu \mathrm{m}$ than blank sample. The greater the $\mathrm{D}[4,3]$ means drugging do better on increasing oil particulate diameter.

\section{Experimental Results and Analysis}

The experimental results are shown in Tables 1-5.

According to the Table 1, oil removal rate increased with the increase of drugging concentration. The change of D10 is not big in blank sample, it shows that the distribution of oil particulate diameter is stable in blank sample. The $V_{1 \mu \mathrm{m}}$ of adding sample is smaller than the $V_{1 \mu \mathrm{m}}$ of blank sample, shows that drugging can reduce oil droplet under $1 \mu \mathrm{m}$. From the Table 1, the D10 of adding sample is bigger than blank sample. With the increase of drugging concentration, drugging increase D10 is more obvious effects. There is no effect when drugging

Table 1. Oil content and D10 in different drugging concentration.

\begin{tabular}{|c|c|c|c|c|c|}
\hline \multirow{2}{*}{$\begin{array}{l}\text { Drugging } \\
\text { concentration }\end{array}$} & \multicolumn{2}{|c|}{ Blank } & \multicolumn{2}{|c|}{ Drugging } & \multirow{2}{*}{$\begin{array}{c}\text { Evaluation index } \\
\qquad \mathrm{P}_{1 \mu \mathrm{m}}\end{array}$} \\
\hline & Oil content mg/l & $\begin{array}{l}\mathrm{D} 10 \\
\mu \mathrm{m}\end{array}$ & Oil content mg/l & $\begin{array}{l}\mathrm{D} 10 \\
\mu \mathrm{m}\end{array}$ & \\
\hline 5 mg/l & 351.75 & 1.68 & 146.16 & 1.81 & $58.45 \%$ \\
\hline $10 \mathrm{mg} / \mathrm{l}$ & 467.2 & 1.64 & 64.1 & 2.06 & $86.28 \%$ \\
\hline $20 \mathrm{mg} / \mathrm{l}$ & 381.56 & 1.82 & 28.72 & 2.35 & $92.47 \%$ \\
\hline
\end{tabular}

Table 2. $\mathrm{V}_{1 \mu \mathrm{m}}$ and $\mathrm{C}_{1 \mu \mathrm{m}}$ in different drugging concentration.

\begin{tabular}{|c|c|c|c|c|c|}
\hline \multirow{2}{*}{$\begin{array}{c}\text { Drugging } \\
\text { concentration }\end{array}$} & \multicolumn{2}{|c|}{ Blank } & \multicolumn{2}{|c|}{ Drugging } & \multirow{2}{*}{$\begin{array}{l}\text { Evaluation index } \\
\qquad \mathrm{P}_{1 \mu \mathrm{m}}\end{array}$} \\
\hline & $\mathrm{V}_{1 \mu \mathrm{m}}(\%)$ & $\mathrm{C}_{1 \mu \mathrm{m}}(\mathrm{mg} / \mathrm{l})$ & $\mathrm{V}_{1 \mu \mathrm{m}}(\%)$ & $\mathrm{C}_{1 \mu \mathrm{m}}(\mathrm{mg} / \mathrm{l})$ & \\
\hline 5 mg/l & 1.36 & 4.78 & 0.7 & 1.02 & 0.214 \\
\hline 10 mg/l & 2.56 & 11.96 & 0.65 & 0.42 & 0.035 \\
\hline 20 mg/l & 1.8 & 6.87 & 0 & 0 & 0 \\
\hline
\end{tabular}

Table 3. Oil content and D10 in different oscillation time.

\begin{tabular}{|c|c|c|c|c|c|}
\hline \multirow{2}{*}{$\begin{array}{l}\text { Oscillation time } \\
\text { min }\end{array}$} & \multicolumn{2}{|c|}{ Oil content (mg/l) } & \multicolumn{2}{|c|}{$\mathrm{D} 10(\mu \mathrm{m})$} & \multirow{2}{*}{$\mathrm{P}_{1 \mu \mathrm{m}}$} \\
\hline & Blank & Drugging & Blank & Drugging & \\
\hline 15 & 862.7 & 342.0 & 1.56 & 1.61 & 60.36 \\
\hline 30 & 528.8 & 143.6 & 1.38 & 1.61 & 72.84 \\
\hline 60 & 486.8 & 188.5 & 1.38 & 1.51 & 61.27 \\
\hline 90 & 363.6 & 162.2 & 1.47 & 1.65 & 55.39 \\
\hline 120 & 335.7 & 123.6 & 1.82 & 1.87 & 63.17 \\
\hline
\end{tabular}


Table 4. $\mathrm{V}_{1 \mu \mathrm{m}}$ and $\mathrm{C}_{1 \mu \mathrm{m}}$ in different oscillation time.

\begin{tabular}{|c|c|c|c|c|c|}
\hline \multirow{2}{*}{$\begin{array}{l}\text { Oscillation time } \\
\text { min }\end{array}$} & \multicolumn{2}{|c|}{$\mathrm{V}_{1 \mu \mathrm{m}}(\%)$} & \multicolumn{2}{|c|}{$\mathrm{C}_{1 \mu \mathrm{m}}(\mathrm{mg} / \mathrm{l})$} & \multirow{2}{*}{$\mathrm{P}_{1 \mu \mathrm{m}}$} \\
\hline & Blank & Drugging & Blank & Drugging & \\
\hline 15 & 1.74 & 0.28 & 15 & 0.96 & 0.064 \\
\hline 30 & 2.13 & 0.98 & 11.26 & 1.41 & 0.125 \\
\hline 60 & 4.01 & 3.64 & 19.52 & 6.86 & 0.35 \\
\hline 90 & 4.1 & 3.7 & 14.91 & 6.00 & 0.403 \\
\hline 120 & 1.71 & 1.51 & 5.74 & 1.87 & 0.325 \\
\hline
\end{tabular}

Table 5. D[4,3] in different oscillation time.

\begin{tabular}{|c|c|c|c|}
\hline \multirow{2}{*}{$\begin{array}{l}\text { Oscillation time } \\
\text { min }\end{array}$} & \multicolumn{2}{|c|}{$\mathrm{D}[4,3](\mu \mathrm{m})$} & \multirow{2}{*}{$\begin{array}{l}\text { The ratio of the volume averag } \\
\text { particle size (drugging/blank) }\end{array}$} \\
\hline & Blank & Drugging & \\
\hline 15 & 2.32 & 2.82 & 1.22 \\
\hline 30 & 2.2 & 18.62 & 8.46 \\
\hline 60 & 3.45 & 17.35 & 5.03 \\
\hline 90 & 22.89 & 33.2 & 1.45 \\
\hline 120 & 19.96 & 73.6 & 3.69 \\
\hline
\end{tabular}

concentration is $5 \mathrm{mg} / \mathrm{L} .20 \mathrm{mg} / \mathrm{L}$ is the best.

According to the Table 2. After the treatment oil droplet under $1 \mu \mathrm{m}$ is reducing with the increase of drugging concentration, which oil droplet under $1 \mu \mathrm{m}$ is minimum when drugging concentration is $20 \mathrm{mg} / \mathrm{L}$. In addition to, effect is all good when drugging concentration of $S 1$ is $10 \mathrm{mg} / \mathrm{L}, 20 \mathrm{mg} / \mathrm{L}$. The $P_{1 \mu \mathrm{m}}$ of water sample is 0 when drugging concentration is $20 \mathrm{mg} / \mathrm{L}$, which means after shaking the adding sample oil droplet under $1 \mu \mathrm{m}$ has become big drop.

Analysis and processing of data with Excel. The experimental results are shown in Figures 1-5.

From Table 3 and Figure 1 we can get that compared with the blank sample the adding sample has less oil content. But with the increase of the oscillation time, oil content in blank sample and adding sample is reducing.

We can get from Table 3 and Figure 2, drugging can increase oil droplets which particle diameter under 1 $\mu \mathrm{m}$ (D10). With the increase of the oscillation time, D10 in blank sample and adding sample is all increasing. This is due to the increase of oscillation time, the oil droplets increase the chance of collision, lead to small oil droplets likely to coalescence together.

From Figure 3 to Figure 4 and Table 4, drugging can decrease oil droplets concentration and content of less than $1 \mu \mathrm{m}$. This means drugging can increase the size of small oil droplets.

With the increase of the oscillation time, the concentration of oil droplets in the size of less than $1 \mu \mathrm{m}$ is increasing. The reason may be that the oscillation time is too long, make some of the oil droplets to break into small oil droplets; or may be large droplets have risen to the top of the simulated water sample, the oil content in the lower part of the water is reduced, which makes the proportion of small oil droplets increase.

Because the $\mathrm{C}_{1 \mu \mathrm{m}}$ is the product of the $\mathrm{V}_{1 \mu \mathrm{m}}$ and the $\mathrm{C}_{\mathrm{i}}$. Therefore, the variation of its oscillation time depends on the oil content and the concentration of oil droplets.

As can be seen from the Table 5 and the Figure 5, drugging can increase the volume average particle diameter of the oil droplets. This indicates that the drugging can increase the particle diameter of the oil droplets. Besides that, with the increase of the oscillation time the volume average particle diameter of the oil droplets increases. This is due to the longer the oscillation time, the greater the chance of the oil droplets collision, the greater the chance that the oil droplets get together and the volume average particle diameter of the oil droplets increases. 


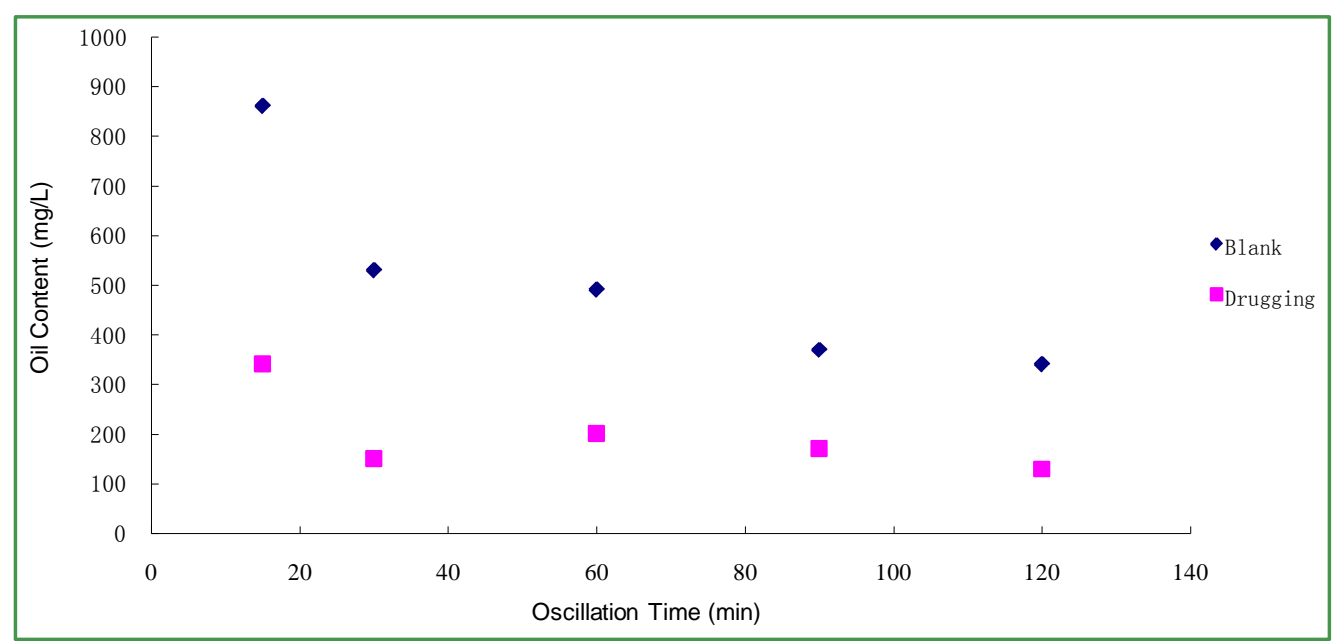

Figure 1. Relation graph of oil content and oscillation time.

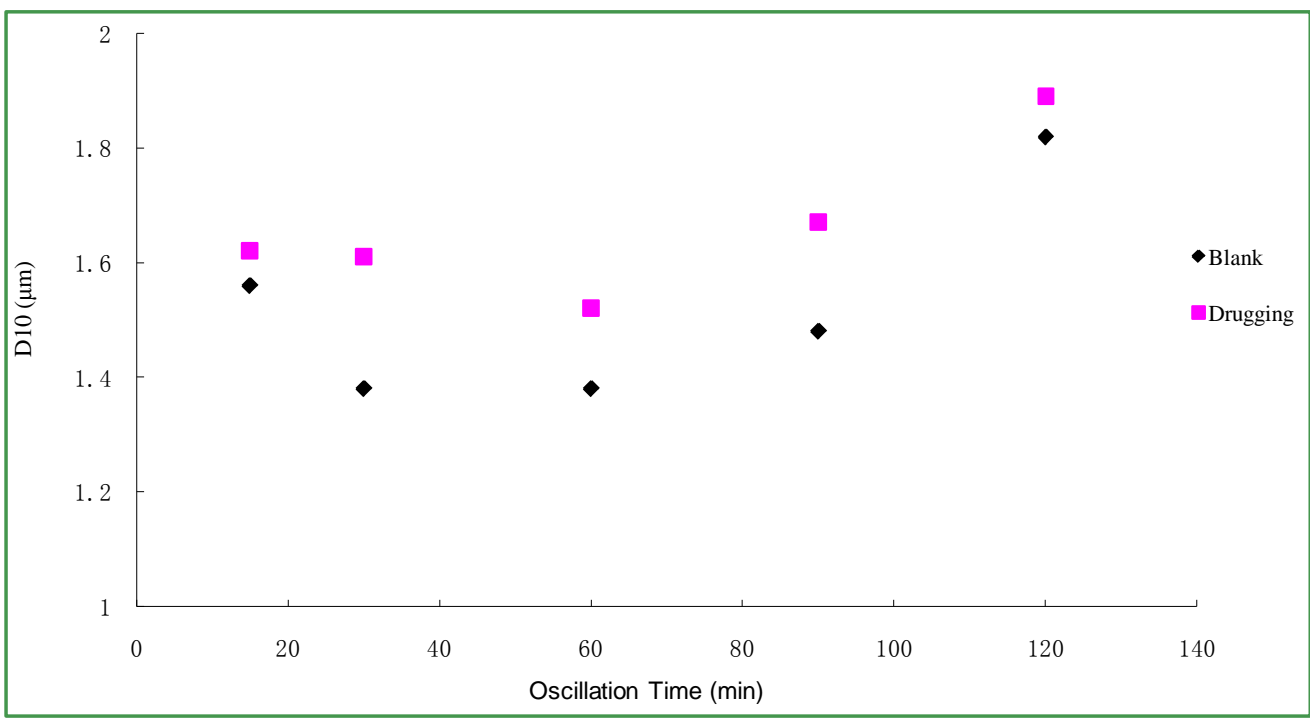

Figure 2. Relation graph of D10 and oscillation time.

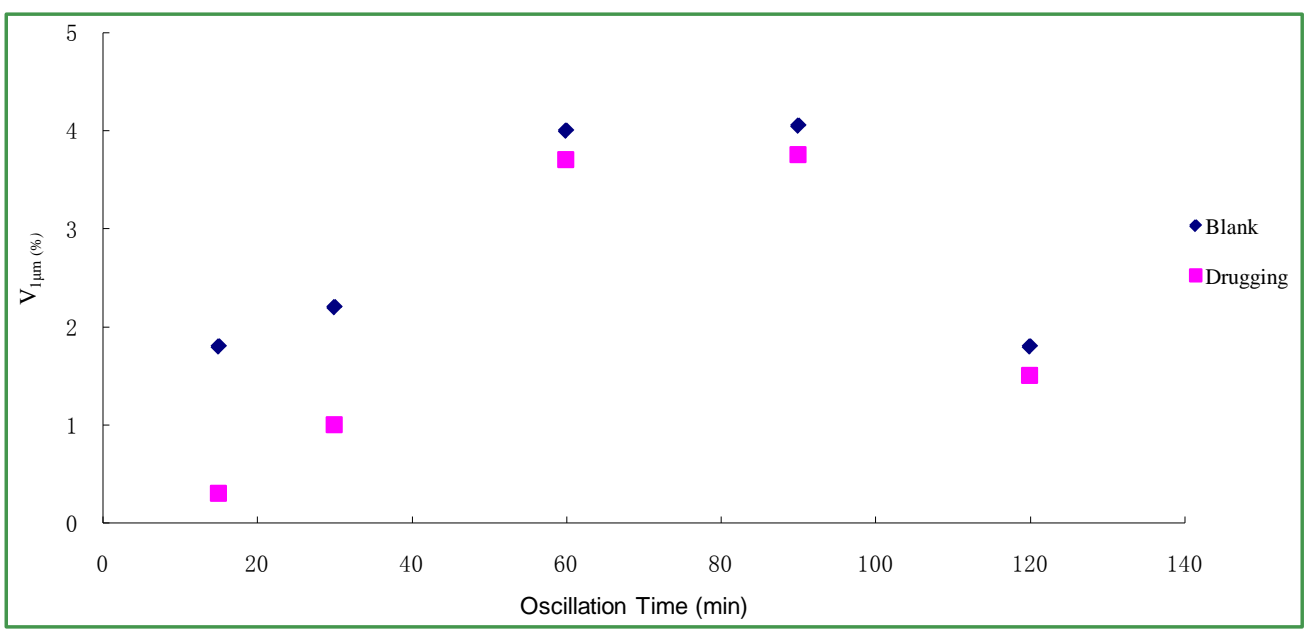

Figure 3. Relation graph of $\mathrm{V}_{1 \mu \mathrm{m}}$ and oscillation. 


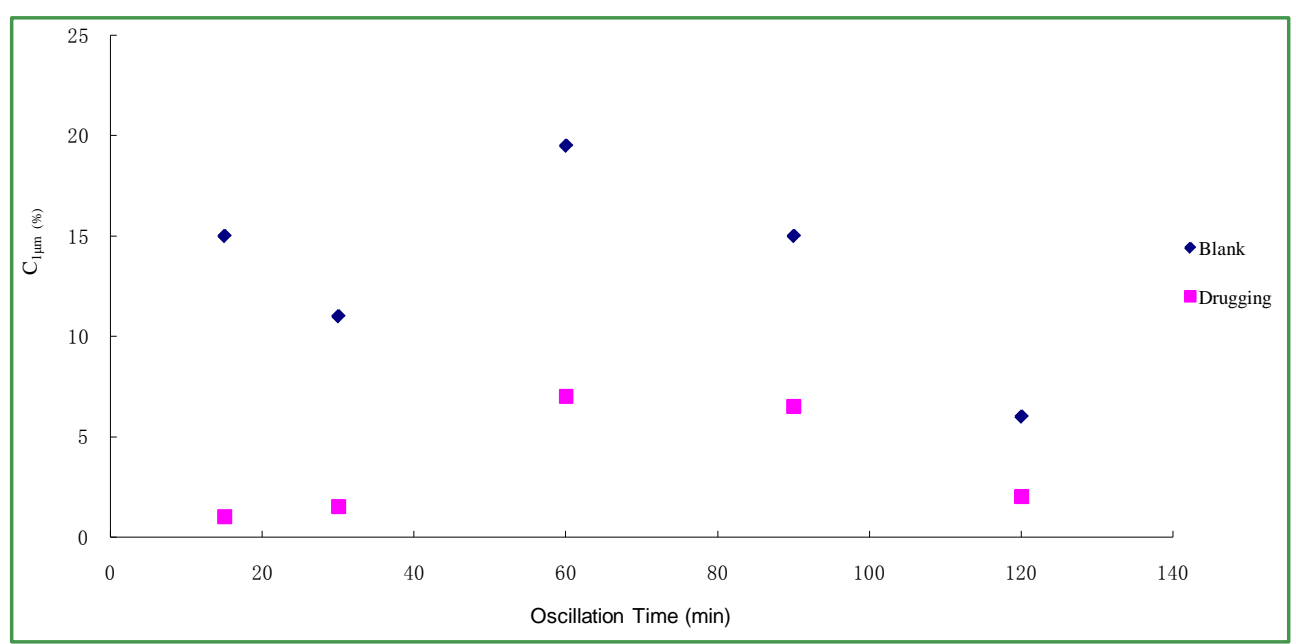

Figure 4. Relation graph of $\mathrm{C}_{1 \mu \mathrm{m}}$ and oscillation time.

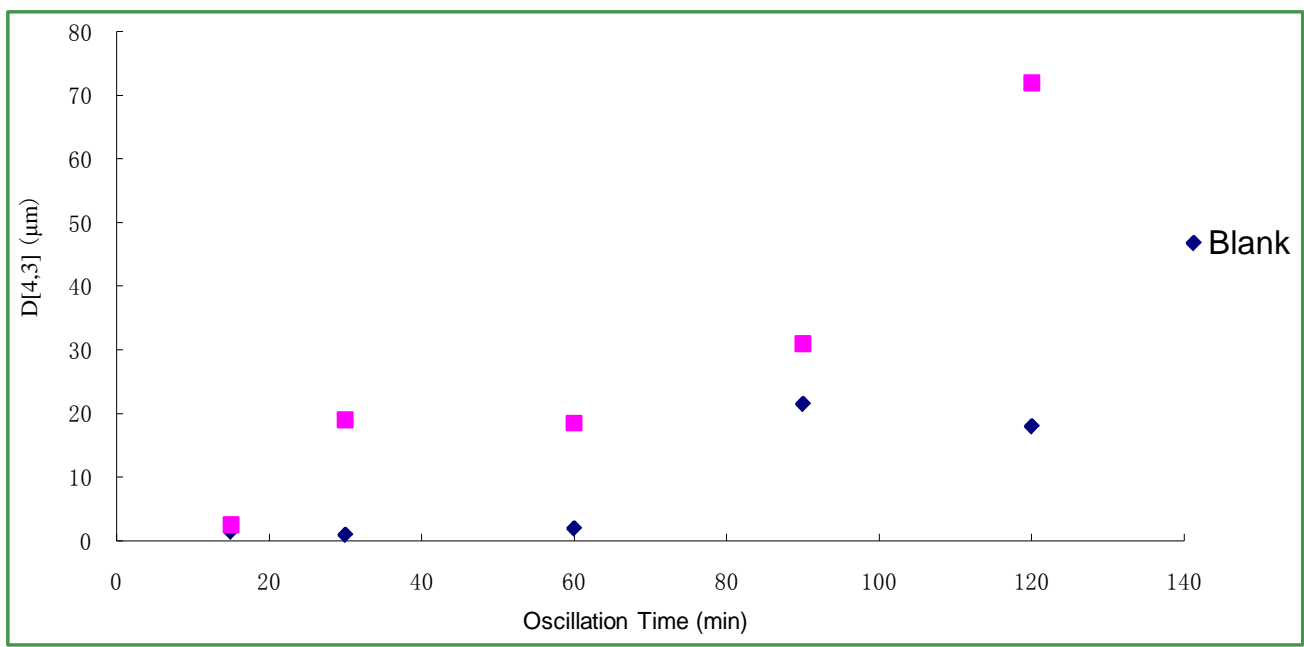

Figure 5. Relation graph of D[4,3] and oscillation time.

\section{Conclusions}

1) Drugging can increase the minimum $10 \%$ particle diameter and the volume of the average particle diameter and decrease the concentration and content of oil droplets under $1 \mu \mathrm{m}$, oil content.

2) With the increase of drug concentration, oil removal rate increased gradually, minimum $10 \%$ particle diameter and volume of the average particle diameter increased, the concentration and content of oil droplets under $1 \mu \mathrm{m}$ is higher.

3) With the increase of the oscillation time, the basic trend is that the oil content is decreased, the minimum $10 \%$ particle diameter and the volume of the average particle diameter increases, the concentration and content of oil droplets under $1 \mu \mathrm{m}$ is higher.

\section{Fund}

This work was supported by the National Natural Science Foundation of China (No: 51404072).

\section{References}

[1] Sun, Z.Q., Wang, Z.B. and Jin, Y.H. (2009) Oil-Water Gravity Separation Principle and Demulsification Mechanism. Chemical Machinery, 36, 636-639. 
[2] Luo, C.L. and Zhu, Q. (2010) Current Situation and Prospect of Oil Wastewater Treatment in Domestic Oil Field. Petroleum Chemical and Equipment, 13, 55-57.

[3] Wu, D., Meng, X.C., et al. (2001) Stability of the Three Element Compound Flooding Produced Water in Daqing Oilfield and its Application in Reverse Phase Emulsion Breaker. Industry of Fine Chemicals, 18, 86-88.

[4] Zhang, Y., Lin, Y.J. and Fan, G.F. (2006) Petroleum and Petrochemical Industrial Wastewater Analysis and Processing. Petroleum Industry Press, Beijing, 7, 60-64.

[5] Zhang, Y.Q. and Gao, B.Y. (2010) Study on the Effect of Polymer Flooding in Shengli Oilfield by Coagulation Process. Journal of Shandong University, 40, 98-102. 